\title{
VARIABILIDADE GENÉTICA EM POPULAÇÕES NATURAIS DE Ziziphus joazeiro Mart., POR MEIO DE MARCADORES MOLECULARES RAPD ${ }^{1}$
}

\author{
Itamara Bomfim Gois², Robério Anastácio Ferreira ${ }^{3}$, Renata Silva-Mann ${ }^{4}$, Silmara Moraes Pantaleão ${ }^{5}$, \\ Camila Bomfim Gois ${ }^{6}$ e Rodrigo Santana Caldas Oliveira ${ }^{7}$
}

\begin{abstract}
RESUMO - Os estudos de diversidade genética em populações naturais são imprescindíveis para a elaboração de estratégias de conservação. Assim, este trabalho foi realizado com o objetivo de caracterizar geneticamente, por meio de marcadores Random Amplified Polymorphic DNA(RAPD), populações naturais de Ziziphus joazeiro Mart., localizadas na região do Baixo São Francisco sergipano. Foram empregados 20 oligonucleotídeos e, a partir do polimorfismo observado, foram estimadas a porcentagem de polimorfismo, a variabilidade genética e a similaridade genética (Sgij), por meio do coeficiente de Jaccard. O teste de Mantel foi realizado para avaliar a correlação entre a similaridade genética e a distância geográfica; sendo o fluxo gênico também estimado. O polimorfismo observado nas populações de Z. joazeiro variou de 58,1 a $66,5 \%$ e a similaridade genética, de 44 a 54\%. A similaridade genética não está correlacionada com a distância geográfica, e os valores observados para o índice de diversidade genética de Nei, para o índice de Shannon e para os parâmetros HS, HT e GST foram considerados altos e semelhantes aos encontrados em outras espécies arbóreas. A porcentagem de locos polimórficos foi considerada baixa. Maior identidade genética foi encontrada entre as populações de Canindé do São Francisco e Santana do São Francisco; e a maior distância genética entre as populações de Canhoba e Canindé do São Francisco. O fluxo gênico foi maior que 1. Com base nos resultados, pode-se afirmar que há alta variabilidade genética entre as populações e que estas podem estar geneticamente estruturadas.
\end{abstract}

Palavras-chave: Joazeiro; Marcadores moleculares; Genética de populações.

\section{GENETIC VARIABILITY IN NATURAL POPULATIONS OF Ziziphus joazeiro Mart., BY RAPD MOLECULAR MARKERS}

\begin{abstract}
The studies of genetic diversity in natural populations are essential to the elaboration of conservation strategies. Thus, this work was carried out to genetically characterize natural populations of Ziziphus joazeiro Mart., by RAPD (Random Amplified Polymorphic DNA) markers, located in the region of Baixo São Francisco, Sergipe. 20 primers were used and, from the observed polymorphism, the genetic similarity (), the characterization of genetic variability and the percentage of polymorphism were estimated by Jaccard's coefficient. The Mantel test was performed to evaluate the correlation between the genetic similarity and the geographic distance and the gene flow was also estimated. The observed polymorphism in the $\mathbf{Z}$. joazeiro populations ranged from 58.1 to $66.5 \%$ and the genetic similarity from 44 to $54 \%$. The genetic similarity observed is not correlated with the geographic distance. The values observed to the Nei's genetic diversity, to the Shannon's index, and to the parameters HS, HT and GST were considered high and similar to those found in other forest species. The percentage of polymorphic loci was considered low. The highest genetic identity was observed between the populations of Canindé do São Francisco, and Santana do São Francisco and the highest genetic distance
\end{abstract}

\footnotetext{
${ }^{1}$ Recebido em 11.09.2012 aceito para publicação em 27.05.2014.

${ }^{2}$ Programa de Pós-Graduação em Fitotecnia, Universidade Federal de Sergipe, Brasil. E-mail: <itamarafloresta@gmail.com>. ${ }^{3}$ Departamento de Ciências Florestais, Universidade Federal de Sergipe, Brasil. E-mail: <roberioaf@yahoo.com.br>.

${ }^{4}$ Departamento de Engenharia Agronômica, Universidade Federal de Sergipe, Brasil. E-mail: <renatamann@hotmail.com>.

${ }^{5}$ Departamento de Biologia, Universidade Federal de Sergipe, Brasil. E-mail: <spleao@yahoo.com.br>.

${ }^{6}$ Programa de Pós-Graduação em Desenvolvimento e Meio Ambiente, Universidade Federal de Sergipe, Brasil. E-mail: $<$ milabgois@hotmail.com.>.

${ }^{7}$ Graduação em Engenharia Florestal, Universidade Federal de Sergipe, Brasil. E-mail: <rodrigo_xyz_2006@hotmail.com>.
} 
between the populations of Canhoba and Canindé do São Francisco. The gene flow was higher than 1. Based on the results it can be stated that there is high genetic variability between the populations, and genetic structuring may be occurring.

Keywords: Joazeiro; Molecular markers; Genetics of populations.

\section{INTRODUÇÃO}

A fragmentação florestal é um processo pelo qual há a divisão das populações naturais em pequenas populações isoladas. Na região do Baixo São Francisco sergipano, a fragmentação é causada, principalmente, pela ocupação humana, pelo uso agrícola da terra e pelo extrativismo; como consequência, a formação de mosaicos de vegetação remanescente é cada vez mais evidenciada, acarretando alterações nos processos ecológicos e genéticos das espécies presentes na região (ESTOPA et al., 2006). Devido à redução do tamanho populacional, gargalos genéticos são criados, pois os indivíduos que restavam continham apenas uma amostra do conjunto gênico original (SEOANE et al., 2005). Além disso, as alterações podem refletir nos padrões de distribuição espacial; no comportamento de espécies relacionadas, como nos polinizadores, afetando, de forma negativa, a sua estrutura genética; e na perda de alelos, reduzindo os níveis de variabilidade genética da espécie (MOURA, 2005).

Diante de tal realidade, são imprescindíveis estudos genéticos em nível populacional das espécies, para que sejam estabelecidas estratégias de conservação genética, procurando reunir subsídios que contribuam para a conservação in situ, manejo sustentável e formação de áreas de coletas de sementes (PINTO; CARVALHO, 2004). O conhecimento da estrutura genética das populações é de suma importância para que seus tamanhos não reduzam abaixo do mínimo viável, comprometendo a perpetuação da espécie. Assim, a maneira muito utilizada para detectar essa variabilidade é por meio de estudos de diversidade genética (BOTREL; CARVALHO, 2004).

$\mathrm{Na}$ caracterização da diversidade genética, basicamente são utilizados quatro tipos de marcadores: morfológicos, bioquímicos, moleculares e citológicos. Os marcadores moleculares apresentam a particularidade de poderem ser utilizados para análise em qualquer estádio de desenvolvimento da planta (KAMADA et al., 2009); além disso, marcadores de DNA são muito eficientes para determinação da variabilidade genética, por analisarem diretamente o material genético (YANAKA et al., 2005).

Revista Árvore, Viçosa-MG, v.38, n.4, p.621-630, 2014
O marcador molecular RAPD (Polimorfismo de DNA Amplificado ao Acaso) tem sido utilizado para detectar a variabilidade genética em populações naturais de forma eficiente. Entre as vantagens citadas dessa técnica, podem-se destacar: simplicidade, rapidez e demanda de quantidades mínimas de DNA. Por utilizar oligonucleotídeo de sequência arbitrária, não é necessário conhecer o genoma da espécie, sendo possível a realização de análises genéticas diretamente em nível de DNA (LACERDA et al., 2002).

Desde o surgimento dessa técnica (WILLIANS et al., 1990), uma gama de estudos tem utilizado o RAPD na realização de análises genéticas com diversas finalidades. Trindade e Chaves (2005) e Freire et al. (2007) comprovaram a sua eficiência estudando a estrutura genética de Eugenia dysenterica e Schizolobium parahyba, respectivamente.

Entre as espécies localizadas na região do Baixo São Francisco sergipano, utilizadas pelas populações locais, pode-se citar Ziziphus joazeiro Mart., que é utilizada nas construções rurais, na produção de lenha e carvão e na alimentação de caprinos e ovinos como recurso alternativo na época da seca (LORENZI, 1992; CARVALHO, 2007). Na medicina popular, é muito empregada no tratamento de gastrites, gripes, contusões e ferimentos e na fabricação de cosméticos, xampus anticaspa e creme dental (MATOS, 2000). Tem sido utilizada também em projetos de recuperação de áreas degradadas na região.

Assim, este trabalho foi realizado com o objetivo de caracterizar geneticamente, por meio de marcadores RAPD, populações naturais de Ziziphus joazeiro Mart. localizadas em diferentes municípios da região do Baixo São Francisco sergipano.

\section{MATERIAL E MÉTODOS}

\subsection{Material vegetal}

Para realização das análises de RAPD (Polimorsfimo de DNA amplificado ao acaso), foram coletadas folhas de 54 indivíduos de Z. joazeiro Mart. (juazeiro) localizados em três municípios do Estado de Sergipe: Canindé do 
São Francisco (15 indivíduos), Alto Sertão Sergipano; Canhoba (19 indivíduos), zona de transição entre a Caatinga e a Mata Atlântica; e Santana do São Francisco (20 indivíduos), Zona Costeira.

A amostragem dos indivíduos foi do tipo aleatória simples, em que se percorreu a área de vegetação ciliar de cada município e selecionaram-se os indivíduos que apresentavam Diâmetro à Altura do Peito (DAP) igual ou superior a $5 \mathrm{~cm}$, respeitando-se uma distância mínima de $50 \mathrm{~m}$ entre eles, uma vez que o espaçamento mínimo recomendado entre árvores-matriz é de 50 a 100 m (KAGEYAMA; GANDARA, 1999). O material foliar coletado foi identificado e mantido em "freezer" até o momento da extração.

\subsection{Extração e amplificação do DNA genômico}

A extração de DNA foi realizada de acordo com o protocolo descrito por Nienhuis et al. (1995), com modificações, sendo a quantificação realizada em gel de agarose $1 \%$, em TBE 0,5X (0,045 M Tris-borato e $0,001 \mathrm{M}$ de EDTA). As alíquotas do DNA foram aplicadas nas canaletas do gel ao lado de uma série de concentrações conhecidas de DNA (20-200 ng), sendo a concentração das amostras estimada por comparação.

As reações de RAPD foram baseadas no método descrito por Willians et al. (1990), usando oligonucleotídeos de 10 bases com sequência arbitrária. Foram empregados 20 oligonucleotídeos da marca IDT (Integrated DNA Technologies), para a geração de polimorfismo. As reações de amplificação foram realizadas em termociclador Uniscience Biometra Tpersonal, em um volume de $13 \mu \mathrm{L}$ contendo $2,92 \mu \mathrm{L}$ de água ultrapura; $1,30 \mu \mathrm{L}$ de tampão PCR $10 \mathrm{X} ; 1 \mu \mathrm{L}$ de cloreto de magnésio $50 \mathrm{mM} ; 1,04 \mu \mathrm{L}$ de dNTP 2,5 mM; $1,04 \mu \mathrm{L}$ de BSA (Soro Albumina Bovina); $0,2 \mu \mathrm{L}$ da enzima Taq DNA polimerase; 2,5 $\mu \mathrm{L}$ do oligonucleotídio iniciador; e $3 \mu \mathrm{L}$ do DNA genômico (SANTANA et al., 2008).

As reações foram submetidas a 45 ciclos de amplificação após a desnaturação inicial a $94{ }^{\circ} \mathrm{C}$, por 2 min. Cada ciclo foi constituído de três temperaturas: $15 \mathrm{seg}$ para desnaturação a $94^{\circ} \mathrm{C}, 30 \mathrm{seg}$ para anelamento do oligonucleotídeo a $42^{\circ} \mathrm{C}$ e $30 \mathrm{seg}$ para extensão da fita de DNA a $72{ }^{\circ} \mathrm{C}$. Ao final dos 45 ciclos, foi realizada uma extensão final de $2 \min$ a $72^{\circ} \mathrm{C}$. Os produtos da amplificação foram separados por eletroforese em cuba horizontal, utilizando-se gel de agarose 1\% em tampão TBE 0,5X, a $100 \mathrm{~V}$, por $90 \mathrm{~min}$. Em seguida, o gel foi corado com brometo de etídio $\left(0,5 \mu \mathrm{g} \mathrm{mL}^{-1}\right)$ por $15 \mathrm{~min}$ e os produtos da amplificação, visualizados e fotografados sob luz ultravioleta.

\subsection{Análise dos dados}

A presença (1) e ausência de bandas (0) foram usadas para a construção de uma matriz binária, a partir da qual foi calculada a porcentagem de polimorfismo obtida com cada oligonucleotídeo utilizado, por meio da equação 1 :

$$
P=\frac{n b p}{n b t} \times 100
$$

em que $P=$ porcentagem de polimorfismo; $n b p$ $=$ número de bandas polimórficas; $n b t=\mathrm{e}$ número de bandas total. As bandas com coloração fraca e baixa definição foram descartadas.

A estimativa de similaridade genética $\left(S g_{i j}\right)$, entre cada par de indivíduos, foi calculada por meio do coeficiente de Jaccard (equação 2):

$$
S g_{i j}=\frac{a}{a+b+c}
$$

em que $a=$ número de casos em que ocorre a presença da banda em ambos os indivíduos; $b=$ número de casos em que ocorre a presença da banda somente no indivíduo i; $c$ = número de casos em que ocorre a presença da banda somente no indivíduo j. A representação simplificada das similaridades foi obtida pela construção do dendrograma pelo método de agrupamento Unweighted Pair-Group Method Arithmetic Average (UPGMA) (SNEATH; SOKAL, 1973). Para verificar se há correlação entre a similaridade genética e a distância geográfica nas diferentes populações analisadas, foi realizado o teste de Mantel (MANLY, 1997), com 1.000 permutações. Essas análises foram executadas com a utilização do programa NTSYS pc2.1. (ROHLF, 2000). Com o objetivo de verificar a consistência de cada agrupamento, foi feita a análise bootstrap, por meio do aplicativo BOOD (COELHO, 2000).

Os erros associados a cada distância genética $\left(1-S g_{i j}\right)$ foram estimados segundo Skroch et al. (1992), por meio da seguinte expressão: $(\mathrm{V} / \mathrm{n})^{1 / 2}$, em que $\mathrm{V}$ é a variância da distância genética entre cada par de indivíduos; e n é o número total de bandas utilizadas na estimativa da distância genética.

Revista Árvore, Viçosa-MG, v.38, n.4, p.621-630, 2014 
Para caracterização da variabilidade genética, foi utilizado o Programa POPGENE (Population Genetic Analysis) versão 1.32 (YEH et al., 1999), utilizando-se parâmetros para dados diploides dominantes. Tendo em vista a natureza dominante dos dados, esse programa pressupõe, para os cálculos das estimativas das frequências alélicas, que os locos estão em Equilíbrio de Hardy-Weinberg. Estimaram-se a diversidade genética de Nei (1978) (He), a porcentagem de locos polimórficos (P\%) e o índice de Shannon, para cada população e para o conjunto de populações. Também, foi realizada a análise de diversidade genética entre populações pelo método de Nei (1978), estimando-se a heterozigosidade total $(\mathrm{Ht})$, a diversidade gênica média dentro de populações (Hs), a divergência genética média entre populações (Gst) e o fluxo gênico (Nm).

\section{RESULTADOS}

O número de fragmentos amplificados na análise RAPD variou de 160 a 203, com média de 8,85 para a população de Santana do São Francisco, 10,15 para a população de Canhoba e 8 para a população de Canindé do São Francisco. O número de fragmentos polimórficos variou de 93 a 135, e o polimorfismo de 58,1 a 66,5\% (Tabela 1).

A similaridade genética média observada na população de Santana do São Francisco foi de 54,0\%, o erro-padrão médio de $4 \%$ e a amplitude das similaridades de 38 a 72\% (Figura 1a). Os indivíduos mais semelhantes foram os $\mathrm{J} 5$ e $\mathrm{J} 6(72 \% \pm 0,04)$ e os mais divergentes, os J3 e J16 (38\% \pm 0,04). Na população de Canhoba, a similaridade genética média foi de $55,0 \%$, o erro-padrão médio de $4 \%$ e a amplitude das similaridades de 32 a $68 \%$. Os indivíduos que se apresentaram mais semelhantes foram os $\mathrm{J} 4$ e J5 $(68 \% \pm 0,04)$ e os mais divergentes, os J3 e J19 (32\% 0,04) (Figura 1b). Já na população de Canindé do São Francisco a similaridade genética média foi igual a 44,0\%, o erro-padrão médio de $4,8 \%$ e a amplitude das similaridades de 26 a $70 \%$. Os indivíduos que se apresentaram mais semelhantes

Tabela 1 - Relação do número de produtos amplificados para cada oligonucleotídeo, com as respectivas porcentagens de polimorfismo (\%P), em análise de RAPD, em populações naturais de Ziziphus joazeiro Mart., localizadas em diferentes municípios do Baixo São Francisco sergipano. NTB - Número total de bandas e NBP - Número de bandas polimórficas.

Table 1 - Number of amplified products for each primer, with their respective percentages of polymorphism (\%P) in RAPD analysis in natural populations of Ziziphus joazeiro Mart., located in different cities of Baixo São Francisco, Sergipe. NTB - Total number of bands; and NBP - Number of polymorphic bands.

\begin{tabular}{|c|c|c|c|c|c|c|c|c|c|c|}
\hline \multirow[t]{2}{*}{ Oligos* } & \multirow[t]{2}{*}{ Sequência $\left(5^{\prime}-3^{\prime}\right)$} & \multicolumn{3}{|c|}{$\underline{\text { Santana do São Francisco }}$} & \multicolumn{3}{|c|}{ Canhoba } & \multicolumn{3}{|c|}{ Canindé do São Francisco } \\
\hline & & NTB & NBP & $\% \mathrm{P}$ & NTB & NBP & $\% \mathrm{P}$ & NTB & NBP & $\% \mathrm{P}$ \\
\hline IDT 1 & CAG GCC CTT C & 10 & 5 & 50,0 & 12 & 7 & 58,3 & 7 & 3 & 42,8 \\
\hline IDT2 & TGC CGA GCT G & 7 & 4 & 57,1 & 10 & 5 & 50,0 & 7 & 4 & 57,1 \\
\hline IDT3 & GTT TCG CTC C & 6 & 3 & 50,0 & 8 & 5 & 62,5 & 9 & 7 & 77,8 \\
\hline IDT 4 & TGA TCC CTG G & 9 & 7 & 77,8 & 7 & 7 & 100,0 & 11 & 9 & 81,8 \\
\hline IDT 5 & TTC GAG CCA G & 7 & 5 & 71,4 & 6 & 4 & 66,7 & 5 & 2 & 40,0 \\
\hline IDT 6 & GTG AGG CGT C & 7 & 5 & 71,4 & 11 & 8 & 72,7 & 7 & 3 & 42,8 \\
\hline IDT 7 & ACC GCG AAG G & 10 & 7 & 70,0 & 11 & 8 & 72,7 & 9 & 6 & 66,7 \\
\hline IDT 8 & GGA CCC AAC C & 7 & 5 & 71,4 & 6 & 4 & 66,7 & 6 & 4 & 66,7 \\
\hline IDT9 & CCC AAG GTC C & 9 & 5 & 55,5 & 13 & 7 & 53,8 & 7 & 4 & 57,1 \\
\hline IDT 10 & GGT GCG GGA A & 12 & 7 & 58,3 & 11 & 6 & 54,5 & 7 & 4 & 57,1 \\
\hline IDT 11 & ACG GAT CCT G & 12 & 9 & 75,0 & 14 & 9 & 64,3 & 13 & 7 & 53,8 \\
\hline IDT 12 & GAG GAT CCC T & 8 & 6 & 75,0 & 12 & 9 & 75,0 & 8 & 4 & 50,0 \\
\hline IDT 13 & CTA CGG AGG A & 12 & 8 & 66,6 & 9 & 5 & 55,5 & 9 & 7 & 77,8 \\
\hline IDT 14 & GGC ACT GAG G & 8 & 4 & 50,0 & 10 & 5 & 50,0 & 9 & 4 & 44,4 \\
\hline IDT 15 & GGT CGG AGA A & 9 & 5 & 55,5 & 10 & 7 & 70,0 & 7 & 4 & 57,1 \\
\hline IDT 16 & TCG GAC GTG A & 9 & 8 & 88,9 & 10 & 7 & 70,0 & 5 & 3 & 60,0 \\
\hline IDT 17 & ACC TGG ACA C & 12 & 4 & 33,3 & 13 & 9 & 69,2 & 10 & 5 & 50,0 \\
\hline IDT 18 & GGA GGA GAG G & 5 & 3 & 60,0 & 7 & 4 & 57,1 & 5 & 2 & 40,0 \\
\hline IDT 19 & CCC GGC ATA A & 10 & 8 & 80,0 & 12 & 12 & 100,0 & 11 & 6 & 54,5 \\
\hline IDT 20 & AAA GTT GGG A & 8 & 4 & 50,0 & 11 & 7 & 63,6 & 8 & 5 & 62,5 \\
\hline TOTAL & & 177 & 112 & 63,3 & 203 & 135 & 66,5 & 160 & 93 & 58,1 \\
\hline
\end{tabular}

* Oligonucleotídeos

* Oligonucleotides.

Revista Árvore, Viçosa-MG, v.38, n.4, p.621-630, 2014 

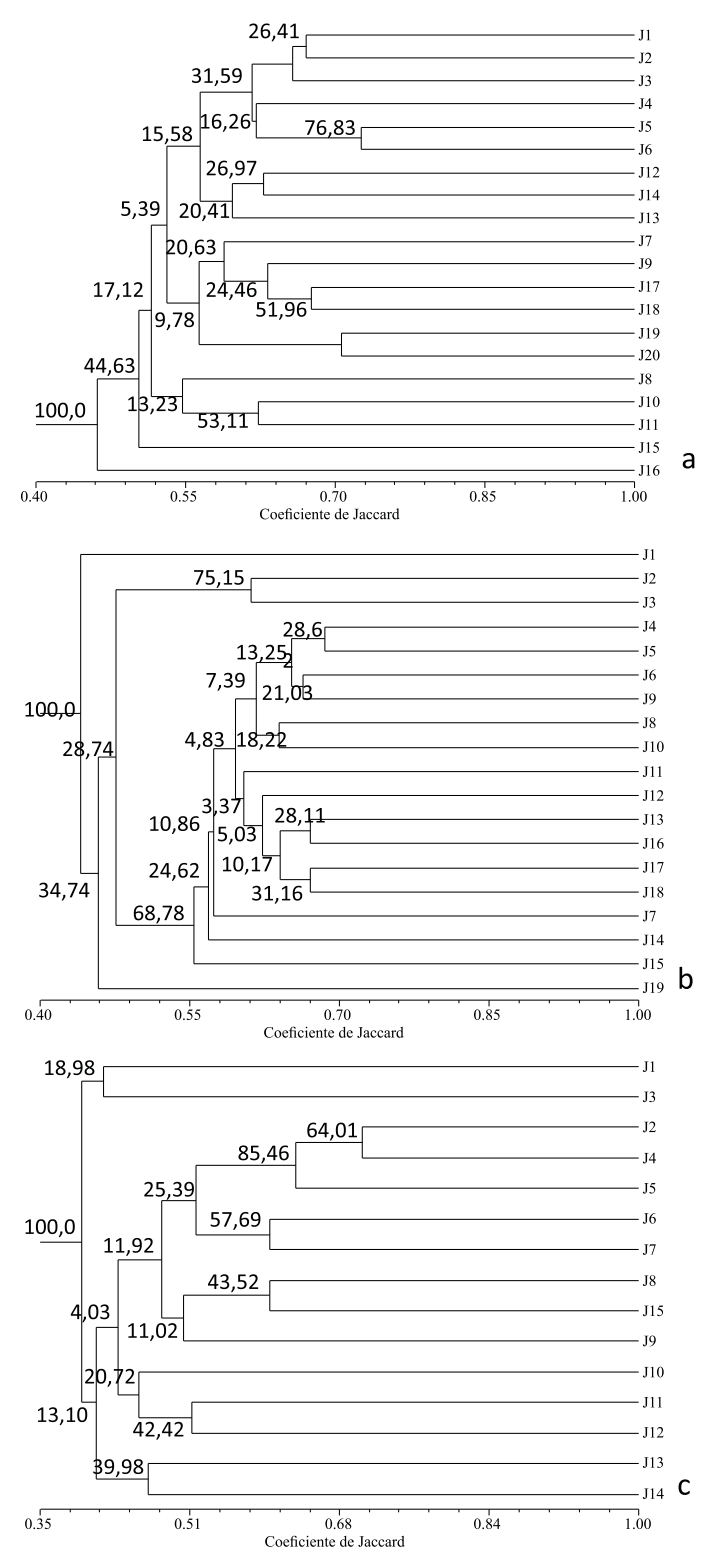

Figura 1 - Dendrograma de similaridade genética entre os indivíduos de Ziziphus joazeiro Mart., definido pelo critério de agrupamento UPGMA, com base no coeficiente de Jaccard, por meio de marcadores RAPD. (a) População natural de Santana do São Francisco; (b) População natural de Canhoba; e (c) População natural de Canindé do São Francisco.

Figure 1-Dendrogram of genetic similarity between individuals of Ziziphus joazeiro Mart., defined by UPGMA grouping, based in the Jaccard's coefficient, by RAPD markers. (a) Natural population of Santana do São Francisco; (b) Natural population of Canhoba; and (c) Natural population of Canindé do São Francisco. foram os $\mathrm{J} 2$ e $\mathrm{J} 4(70 \% \pm 0,04)$ e os mais divergentes, os J3 e J13 $(26 \% \pm 0,05)$ (Figura 1c).

O teste de Mantel revelou correlação negativa $(-1,2530)$ e não significativa $(0,1051)$ para a população de Santana do São Francisco, negativa $(-0,40335)$ e significativa $(0,0001)$ para a população de Canhoba e positiva $(0,3299)$ e não significativa $(0,6293)$ para a população de Canindé do São Francisco.

Os índices de diversidade genética entre as populações estão apresentados na Tabela 2. A heterozigosidade, também chamada de índice de diversidade genética de Nei, variou de 0,2451 a 0,3093; o Índice de Shannon, de 0,3602 a 0,4652; e a porcentagem de locos polimórficos, de 63,70 a 92,47\%.

Os parâmetros estimados da diversidade genética de Nei estão apresentados na Tabela 3. Observa-se, nessa tabela, que $24 \%$ da variabilidade genética se encontra entre as populações $(0,2458)$ e $76 \%$, dentro das populações $\left(\mathrm{H}_{\mathrm{S}}=0,2695\right)$. O valor do fluxo gênico é considerado baixo $(1,5344)$.

As medidas de distância genética e identidade genética de Nei (1978) estão apresentadas na Tabela 4. A maior identidade genética foi observada entre as populações de Canindé do São Francisco e Santana do São Francisco $(0,8710)$, sendo a maior distância genética verificada entre as populações de Santana do São Francisco e Canhoba $(0,2632)$.

\section{DISCUSSÃO}

Com a utilização de 20 oligonucleotídeos para o estudo da divergência genética em populações naturais de Z. joazeiro, foram gerados pelo menos dois fragmentos polimórficos de DNA por oligonucleotídeo.

O número de fragmentos polimórficos utilizados para a avaliação da variabilidade genética em plantas é bastante variável. Santana et al. (2008) utilizaram 37 fragmentos de DNA para a caracterização da diversidade genética de Enterolobium contortisiliquum (Vell.) Morong.; e Bessega et al. (2000), utilizaram quatro oligonucleotídeos, a partir dos quais obtiveram 46 fragmentos polimórficos, que foram suficientes para determinar a diversidade genética entre indivíduos de Prosopis glandulosa (Torr.) Standl. e P. velutina Wood. Observou-se que, como nesses estudos são utilizadas populações naturais, em um número reduzido de oligonucleotídeos é encontrado elevado polimorfismo. 
Tabela 2 - Índice de diversidade de Shannon (1972), diversidade genética de Nei (1978) e porcentagem (\%) de locos polimórficos em populações naturais de Ziziphus joazeiro Mart., localizadas em diferentes municípios do Baixo São Francisco sergipano.

Table 2 - Shannon's diversity index (1972), Nei's genetic diversity (1978), and Percentage (\%) of polymorphic loci in natural populations of Ziziphus joazeiro Mart., located in different cities of Baixo São Francisco, Sergipe.

\begin{tabular}{lccc}
\hline Populações & Diversidade genética de Nei & Índice de Shannon & \% Locos polimórficos \\
\hline Santana do São Francisco & 0.2539 & 0.3815 & 76,71 \\
Canhoba0.3093 & 0.4652 & 92,47 & 63,70 \\
Canindé do São Francisco & 0.2451 & 0.3602 & 100,0 \\
Conjunto de populações & 0.3601 & 0.5344 & \\
\hline
\end{tabular}

Tabela 3 - Diversidade genética de Nei em populações naturais de Ziziphus joazeiro Mart., localizadas em diferentes municípios do Baixo São Francisco sergipano. $\mathrm{H}_{\mathrm{T}}$ = diversidade genética total (heterozigosidade); $\mathrm{H}_{\mathrm{S}}=$ diversidade genética dentro das populações; $\mathrm{G}_{\mathrm{ST}}=$ relação entre a diversidade genética entre populações e a diversidade genética total; e $\mathrm{Nm}=$ fluxo gênico.

Table 3 - Nei's genetic diversity in natural populations of Ziziphus joazeiro Mart., located in different cities of Baixo São Francisc, Sergipe. $H_{T}=$ Total genetic diversity (heterozygosity); $H_{S}=$ Genetic diversity within populations; $G_{S T}$ $=$ Relation between genetic diversity among populations and the total genetic population; and Nm = gene flow.

\begin{tabular}{cccc}
\hline & $\mathrm{H}_{\mathrm{T}}$ & $\mathrm{H}_{\mathrm{S}}$ & $\mathrm{G}_{\mathrm{ST}}$ \\
\hline Média & 0,3573 & 0,2695 & 0,2458 \\
Desvio-padrão & 0,0174 & 0,0151 & 1,5344 \\
\hline
\end{tabular}

Tabela 4 - Medidas originais de distância genética e identidade genética de Nei entre populações naturais de Ziziphus joazeiro Mart., localizadas em diferentes municípios do Baixo São Francisco sergipano.

Table 4 - Original measures of Nei's genetic distance and identity among natural populations of Ziziphus joazeiro Mart., located in different cities of Baixo São Francisco, Sergipe.

\begin{tabular}{lccc}
\hline & Santana do São Francisco & Canhoba & Canindé do São Francisco \\
\hline Santana do São Francisco & - & 0,7686 & 0,8710 \\
Canhoba & 0,2632 & - & 0,8186 \\
Canindé do São Francisco & 0,1381 & 0,2001 & - \\
\hline
\end{tabular}

* Valores acima da diagonal correspondem à identidade genética e abaixo da diagonal, à distância genética.

* Values above the diagonal correspond to genetic's identity and below the diagonal, the genetic's distance.

Colombo et al. (2000) afirmaram que a utilização de 50 a 100 bandas é considerada suficiente para estimar as relações genéticas entre e dentro de espécies vegetais. Entretanto, mesmo com um número de bandas polimórficas superior a 50 em todas as populações, não foi observada a estabilização de alguns agrupamentos na análise de bootstrap realizada nas populações. Essa análise revela a consistência interna dos dados, ou seja, se a topologia mudar com a reamostragem dos dados, menor será o valor da proporção do bootstrap e, portanto, menor a segurança que se pode ter nela (VIEIRA et al., 2007). Assim, os ramos que são considerados pouco consistentes (menor que 60\%) ocorrem devido à variação na informação produzida pelos locos, ou seja, mudando-se os locos, estes grupos não são necessariamente reproduzidos (GONÇALVES et al., 2008).
Os polimorfismos observados nas populações com os oligonucleotídeos utilizados são considerados baixos, indicando que elas apresentam baixa heterozigosidade e alguns processos ecológicos, como o fluxo gênico, não estão ocorrendo entre as populações. Valores próximos ao observado neste estudo foram encontrados por Bertoni et al. (2007) ao estudarem oito populações de Zeyheria montana Mart. (média de 60\%). No entanto, Freire et al. (2007) observaram que populações naturais de Schizolobium parahyba (Vell.), distantes entre si 64 a $350 \mathrm{~km}$, apresentaram elevado polimorfismo (96,9\%).

As similaridades genéticas médias observadas nas populações de $Z$. joazeiro variaram de 44 a 54\%, indicando que há divergência genética entre os indivíduos e que estes podem ser utilizados na produção e colheita de sementes e produção de mudas para 
recuperação de áreas degradadas. Em geral, a variação genética entre populações pode ser o resultado da distância geográfica e das zonas ecológicas (MILANKOV et al., 2007). No entanto, neste estudo a distância geográfica das populações não está relacionada com a similaridade genética entre os indivíduos analisados, o que pôde ser constatado por meio do teste de Mantel. A partir desse teste, pôde-se observar que as populações de Santana do São Francisco e Canhoba apresentaram correlação negativa entre a similaridade genética e a distância geográfica e que na população de Canindé do São Francisco o valor de correlação foi positivo. No entanto, a similaridade genética não pôde ser explicada pela distância geográfica, uma vez que o teste estatístico não suportou a tendência observada. Esse fato também foi verificado por Cavallari Neto (2004), estudando populações de Tabebuia cassinoides LAM (D.C.).

A heterozigosidade foi usada para avaliar o conteúdo polimórfico de cada loco, sendo os valores obtidos $(0,2451$ a 0,3093$)$ semelhantes aos encontrados por Tambarussi et al. (2008) ao estudarem nove populações naturais de Piptadenia gonoacantha Mart. (média de $0,292)$ e por Freire et al. (2007) em populações de Schizolobium parahyba Vell. $(0,36)$.

O Índice de Shannon varia de 0 a 1, e considera-se que, quanto mais próximo o valor for de zero, mais baixas são as diversidades (BOTREL et al., 2006). Nas populações estudadas de $Z$. joazeiro, os valores desse índice $(0,3602$ a 0,4652$)$ foram próximos aos encontrados por Estopa et al. (2006), estudando populações naturais de Eremanthus erythropappus (DC.) MacLeish (0,49 e 0,50).

O baixo nível de locos polimórficos observado nas populações de Santana do São Francisco e Canindé do São Francisco indica que elas estão isoladas, situação também constatada por Zimback et al. (2004) estudando populações de Trichilia pallida Swartz. A perda de heterozigosidade geralmente está associada aos eventos aleatórios de colonização e à deriva genética (PEREIRA et al., 2004).

A espécie apresenta reserva de variabilidade genética nas populações estudadas, o que pode ser comprovado pelo valor da heterozigosidade total verificada $(0,3573)$. A divergência genética foi relativamente alta, demonstrando que $24 \%$ da variabilidade genética se encontrava entre as populações
$(0,2458)$ e $76 \%$ dentro das populações $\left(H_{S}=0,2695\right)$, em concordância com a grande quantidade observada de alelos exclusivos, o que sugere fortes restrições no fluxo gênico (FERREIRA-RAMOS, 2008). A maior diversidade genética dentro de populações tem sido encontrada em outras espécies arbóreas, como Trichilia pallida Swartz, estudada por Zimback et al. (2004).

Segundo Lovelless e Hamrick (1984), muitas espécies arbóreas possuem efetivos meios de dispersão de genes e, com isso, mantêm altos níveis de variação genética dentro de populações, com pouca diferenciação entre estas. No entanto, maior diferenciação genética é esperada entre populações geográfica e reprodutivamente isoladas entre si, fato esse observado nas populações estudadas de Z joazeiro.

O valor do fluxo gênico observado $(1,5344)$ nessas populações pode ser indicativo de isolamento genético, o que está associado à distância geográfica entre elas. $\mathrm{O}$ valor de $\mathrm{Nm}$ determina se a deriva genética, por si só, pode produzir variabilidade genética substancial entre locais; se esse valor for maior que 1.0, o fluxo gênico será alto o suficiente para prevenir diferenciação devida à deriva (MORAES; DERBYSHIRE, 2002). No entanto, o valor observado corresponde ao fluxo gênico histórico, quando as populações faziam parte de uma única grande população ou constituíam metapopulações. Assim, a interpretação desse dado deve ser feita com cautela, pois indica que as populações de diferentes regiões, apesar de geograficamente isoladas, apresentam alelos e frequências similares, como resultado de trocas gênicas antigas (RAPOSO et al., 2007).

Observou-se que, embora as populações de Canindé do São Francisco e Santana do São Francisco estivessem mais distantes geograficamente, elas apresentaram a menor distância genética, inferior à das populações mais próximas (Santana do São Francisco e Canhoba). A correlação entre a distância geográfica e a divergência genética entre as populações no teste de Mantel foi nula e não significativa $(0,500)$. Tal resultado indica que as populações não estão isoladas por distância; logo, a divergência genética entre elas não pode ser explicada pela distância geográfica (LOSS et al., 2006), sendo a deriva genética a causa mais provável (SOUZA et al., 2004).

A distribuição da variabilidade genética entre e dentro de populações evidenciou a presença de certa estrutura genética, que, porém, não foi correlacionada

Revista Árvore, Viçosa-MG, v.38, n.4, p.621-630, 2014 
com a distribuição espacial das populações. Loveless e Hamrick (1984) afirmaram que a diferenciação entre as populações tende a ser reduzida quando as espécies apresentam fertilização cruzada e fluxo de pólen, porém, devido à ausência de fluxo gênico entre as populações, foi observada diferenciação entre elas. Outro fator que influencia na estruturação das populações naturais é o agente polinizador da espécie. As espécies que são polinizadas por insetos possuem baixa variabilidade e reduzido tamanho efetivo e, devido ao movimento limitado desses animais, a estruturação das populações é observada (LOVELESS; HAMRICK, 1984).

\section{CONCLUSÕES}

O uso de marcadores RAPD permitiu a caracterização genética das populações naturais de Ziziphus joazeiro Mart., localizadas em diferentes municípios da região do Baixo São Francisco sergipano.

Apesar do processo de fragmentação florestal observado na área, foi constatada alta variabilidade genética dentro das populações.

A alta variabilidade genética entre as populações é, provavelmente, decorrente da distância geográfica entre elas e das características ecológicas da espécie.

\section{AGRADECIMENTOS}

À Fundação de Amparo à Pesquisa e à Inovação Tecnológica do Estado de Sergipe (FAPITEC), pela concessão da bolsa de mestrado à primeira autora; e ao Banco do Nordeste, pelo financiamento do projeto.

\section{REFERÊNCIAS}

BERTONI, B. W. et al. Genetic variability in natural populations of Zeyheria montana Mart. from the Brazilian cerrado. Scientia Agricola, v. 64, p. $409-415,2007$.

BESSEGA, C.; SAIDMAN, B. O.; VILARDI, J. C. Isozyme and RAPD studies in Prosopis glandulosa and P. Velutina (Leguminosae, Mimosoideae). Genetics and Molecular Biology, v.23, n.3, p. 639-648, 2000.

BOTREL, M. C.; CARVALHO, D. Variabilidade isoenzimática em populações naturais de jacarandá paulista (Machaerium villosum Vog.). Revista Brasileira de Botânica, v.27, n.4, p.621-627, 2004.

Revista Árvore, Viçosa-MG, v.38, n.4, p.621-630, 2014
BOTREL, M. C. G. et al. Caracterização genética de Calophyllum brasiliense camb. em duas populações de mata ciliar. Revista Árvore, v.30, n.5, p.821-827, 2006.

CARVALHO, P. E. R. Juazeiro - Ziziphus joazeiro. Colombo: Embrapa, 2007. (Circular Técnica, 139)

CAVAlLARI NETO, M. Efeito do manejo na diversidade genetic de populaces naturais de Tabebuia cassinoides Lam. (DC), por marcadores isoenzimáticos. 2004. 67f. Dissertação (Mestrado em Recursos Florestais) - Escola Superior de Agricultura Luiz de Queiroz, Piracicaba, 2004.

COELHO, A. S. G. BOOD: avaliação de dendrogramas baseados em estimativas de distâncias/similaridades genéticas através do procedimento de bootstrap. Goiânia: Universidade Federal de Goiás, 2000.

COLOMBO, C.; SECOND, G.; CHARRIER, A. Diversity within american cassava germplasm based on RAPD markers. Genetics and Molecular Biology, v.23, n.1, p.189-199, 2000.

ESTOPA, R. A. et al. Diversidade genética em populações naturais de candeia (Eremanthus erythropappus (DC.) MacLeish). Scientia Forestalis, n.70, p.97-106, 2006.

FERREIRA-RAMOS, R. Estrutura genética e fluxo gênico em populações naturais de Eugenia uniflora L.na região de RibeirãoPreto(SP), utilizando marcadores microssatélites. 2008. 165 f. Dissertação (Mestrado em Ciências) - Faculdade de Filosofia, Ciências e Letras de Ribeirão Preto; Universidade de São Paulo Ribeirão Preto, 2008.

FREIRE, J. M. et al. Estrutura genética de populações de Schizolobium parahyba (Vell.) Blake (guapuruvu) por meio de marcadores RAPD. Scientia Forestalis, n. 74, p. 27-35, 2007.

GONCALVES, L. S. A. et al. Divergência genética em tomate estimada por marcadores RAPD em comparação com descritores multicategóricos. Horticultura

Brasileira, v.26, n. 3, p. 364-370, 2008. 
KAGEYAMA, P. Y.; GANDARA, F. B.

Restauração, conservação genética e produção de sementes. ln: SIMPÓSIO MATA CILIAR: CIÊNCIA E TECNOLOGIA, 1999., Belo Horizonte. Anais... Lavras: Universidade Federal de Lavras, 1999. p.59-68.

KAMADA, T. et al. Diversidade genética de populações naturais de Diversidade genética de populações naturais de Pfaffia glomerata (Spreng.) Pedersen estimada por marcadores RAPD. Acta Scientiarum Agronomy, v. 31, n.3, p.403-409, 2009.

LACERDA, D. R. et al. A técnica de RAPD: uma ferramenta molecular em estudos de conservação de plantas. Lundiana, v.3, n.2, p.87-92, 2002.

LORENZI, H. Árvores brasileiras: manual de identificação e cultivo de plantas arbóreas nativas do Brasil. Nova Odessa: Plantarum, 1992. 384p

LOSS, A. C. C.; LEITE, Y. L. R.; LOURO, I. D. Diversidade genética de populações de maracujádoce (Passiflora alata Curtis) no estado do Espírito Santo, Brasil. Natureza on line, v.4, n.2, p.55-61, 2006. Disponível em: <http:// www.naturezaonline.com.br>

LOVELESS, M. D.; HAMRICK, J. L. Ecological determinants of genetic structure in plant populations. Annual Review of Ecology and Systematics, n.15, p.65-95, 1984.

MANLY, B. F. J. Randomization, bootstrap and Monte Carlo methods in biology. London: Chapman \& Hall, 1997.

MAtos F. J. A. Plantas medicinais: guia de seleção e emprego de plantas usadas em fitoterapia no Nordeste do Brasil. 2.ed. Fortaleza: Universidade Federal do Ceará, 2000. 346p.

MILANKOV, V.; STAMENKOVIÆ, J.; VUJIÆ, A. Genetic differentiation and linkage disequilibrium in a spatially fragmented population of Cheilosia vernalis (Diptera: Syrphidae) from the Balkan peninsula. Acta Zoologica Academiae Scientiarum, v.53, n.2, p.193-201, 2007.

MORAES, P. L. R.; DERBYSHIRE, M. T. V. C. Estrutura genética de populações naturais de Cryptocarya aschersoniana Mez (Lauraceae) através de marcadores isoenzimáticos. Biota Neotropical, v.2, n.2, p. 1-19, 2002.
MOURA, M. C. O. Distribuição da variabilidade genética em populações naturais de Eremanthus erythropappus (DC.) MacLeish por isoenzimas e RAPD. 2005. (165f.) Tese (Doutorado em Engenharia Florestal) - Universidade Federal de Lavras, Lavras, 2005.

NEI, M. Estimation of average heterozygosity and genitic distance from a small number of individuals. Genetics, v.87, n. 3, p.583-590, 1978.

NIENHUIS, J. et al. Genetic relationships among cultivars and lines of lima bean (Phaseolus lunatus L.) as measured by RAPD markers. Journal of the American Society for Horticultural Science, v.120, n.2, p.300306, 1995.

PEREIRA, M. F. et al. Estrutura genética de populações de espécies arbóreas nativas do cerrado encontradas em terrenos serpentínicos. Pesquisa Agropecuária Tropical, v.34, n.2, p.75-82, 2004.

PINTO, S. I. C.; CARVALHO, D. Estrutura genética de populações de pindaíba (Xylopia brasiliensis Sprengel) por isoenzimas. Revista Brasileira de Botânica, v.27, n.3, p.597605, 2004.

RAPOSO, A. et al. Diversidade genética de populações de andiroba no Baixo Acre.

Pesquisa Agropecuária Brasileira, v.42, n.9, p.1291-1298, 2007.

ROHLF, F. J. Numerical taxonomy and multivariate analysis system. Version 2.1. New York: Exeter Software, 2000. 38p.

SANTANA, G. C. et al. Diversidade genética de Enterolobium contortisiliquum (Vell.) Morong. no Baixo Rio São Francisco, por meio de marcadores RAPD. Revista Árvore, v.32, n.3, p. 427-433, 2008.

SEOANE, C. E. S. et al. Efeitos da fragmentação florestal sobre a imigração de sementes e a estrutura genética temporal de populações de Euterpe edulis Mart. Revista do Instituto Florestal, v.17, n.1, p.25-43, 2005.

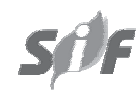

Revista Árvore, Viçosa-MG, v.38, n.4, p.621-630, 2014 
SKROCH, P. W.; TIVANG, J.; NIENHUIS, J. Analysis of genetic relationship using RAPD marker data. In: IUFRO INTERNATIONAL CONFERENCE: "Breeding tropical trees" Section 202-08, 1992, Cali, Colombia. Proceedings... Cali: 1992. p.26-30.

SNEATH, P. H.; SOKAL, R. R. Numerical taxonomy: the principles and practice of numerical classification. San Francisco: W. H. Freeman, 1973.

SOUZA, L. M. F. I.; KAGEYAMA, P. Y.; SEBBENN, A. M. Estrutura genética em populações fragmentadas de Chorisia speciosa $\mathrm{St}$ Hil (Bombacaceae). Scientia Forestalis, n.65, p.70-79, 2004.

TAMBARUSSI, E. V. et al. Tambarussi et al. Estrutura genética de populações de Piptadenia gonoacantha (Mart.) Macbr. por meio de marcadores moleculares RAPD. Revista Científica Eletrônica de Engenharia Florestal, v, 7, n.12, P.1-15, 2008.

TRINDADE, M. G.; CHAVES, L. J. Genetic structure of natural Eugenia dysenterica DC (Myrtaceae) populations in northeastern Goiás,
Brazil, acessed by morphological traits and RAPD markers. Genetics and Molecular Biology, v.28, n.3, p.407-413, 2005.

VIEIRA, V. C. et al. Variabilidade genética em acessos de trapoeraba (Commelina benghalensis L.). Arquivo do Instituto de Biologia, v.74, n.4, p.315-320, 2007.

WILLAMS, J. G. K. et al. DNA polymorphisms amplified by arbitrary primers are useful as genetic markers. Nucleic Acids Research, v.18, n.22, p.6531-6535, 1990.

YANAKA, F. Y. Variabilidade genética em populações naturais de Bromus auleticus Trin. ex Nees (Poaceae) com base em isoenzimas e marcadores RAPD. Revista Brasileira de Zootecnia, v.34, n.6, p.1897-1904, 2005.

YEH, F. C.; YANG, R.; BOYLE, T. POPGENE version 1.32: Microsoft Window-based freeware for population genetics analysis. Edmonton: University of Alberta, 1999.

ZIMBACK, L. et al. Estrutura genética de populações de Trichilia pallida Swartz (Meliaceae) por marcadores RAPD. Scientia Forestalis, n.65, p.114-119, 2004. 